\title{
Rótulos, ah! Os rótulos...
}

Frederico de Holanda. Universidade de Brasília, Brasília, DF, Brasil.

\section{Introdução}

Estou entre os privilegiados por conhecer Bill Hillier (1937-2019) décadas atrás, quando a expressão "sintaxe espacial" foi publicamente impressa por primeiro: era o ano de 1976 e, o lugar, o fascinante ambiente intelectual formado por ele, Julienne Hanson e outros colegas na Bartlett (UCL, Londres).

Desde então fui estimulado por suas ideias seminais, primeiro como estudante de mestrado, depois quando ele orientou minha dissertação e, depois ainda, minha tese de doutorado. Para minha alegria nossa relação não terminou aí, pois nos reencontramos em Brasília (veio três vezes), ${ }^{1}$ Londres, Atlanta, Estocolmo, Istanbul, Santiago...

Melhor que teorias ou interpretações específicas (sim, elas são admiráveis), isto é o que mais acalento, e pelo que serei eternamente grato: reaprendi a pensar a Arquitetura, a influência de Bill na minha carreira (assim me permito tratá-lo aqui) deuse mais no campo epistemológico que no campo da ciência, mais como um saber sobre os saberes do que como um saber sobre o mundo.

Estas breves notas, oportunamente sugeridas por Vinicius Netto e demais colegas editores da Revista de Morfologia Urbana para compor uma seção especial dela, foram escritas ainda sob a emoção de sua perda, em 5 de novembro passado. $O$ generoso leitor perdoará o tom pessoal e a abordagem preliminar do tema, dados o tempo e o espaço disponíveis, e, last but not least, as limitações deste escriba. Na seleção dos tópicos deixei correr livre a subjetividade: na miríade de ideias com que deparei em quatro décadas de convívio, em quais minha mente mais repousa? Como permito-me fazer uma leitura relativamente pessoal delas?

\section{O axioma}

Começar pelo começo: eis o axioma central da Teoria da Lógica Social do Espaço (ou Teoria da Sintaxe Espacial, sua outra denominação, doravante SE), exposta com maior completude por primeiro em The social logic of space (1984, doravante SLS) que Bill assina com Julienne Hanson: $o$ espaço é função de formas de solidariedade social, e seu duplo corolário: 1) as sociedades humanas não existem no éter, são um fenômeno concreto composto por corpos que se movimentam no espaço e no tempo, cujos padrões reconhecíveis (concentrações, dispersões) são constituídos no chão - o melhor termo - por 2) um sistema de barreiras e permeabilidades ao movimento dos corpos e de opacidades e transparências à sua mútua visão que já nasce social, pois, conscientemente ou não, o sistema implica classificar, juntar, separar, enfim ordenar corpos socialmente determinados (Hillier \& Hanson, 1989).

A SE delimita um campo de investigação da arquitetura que diz respeito ao modo de esta constituir sistemas de convívio; não refere outras dimensões, como a ambiental, a simbólica ou a estética. Por outro lado, o livro SLS é exemplo primoroso das relações entre teoria e história, ao ilustrar quão impossível é fazer teoria sem história, ou história sem teoria (se queremos fazê-las a sério, pelo menos em nosso campo - na física teórica são outros quinhentos): uma teoria sem história resume-se a conjecturas porventura poéticas, contudo alheias à realidade dos fatos; uma história sem teoria pode ser uma escrita ficcional pitoresca, mas escorrega facilmente para um relato desinteressante de datas, pessoas, eventos, lugares. A SE evita ambas as armadilhas.

\section{Variável dependente $x$ variável independente}

Desde os seminários de Bill dos anos 1970 trago a importância de Anthony Giddens (Giddens, 1973; 1984), quando este discute o círculo virtuoso das práticas humanas: nossas ações partem de determinações econômicas, políticas e ideológicas (da tríade marxista clássica, às quais podemos acrescentar as ambientais), materializam-se, p. ex., em edifícios e cidades, que resultam numa outra realidade, agora transformada, reconfigurando os pressupostos da tríada - ou da quadríade - portanto operando efeitos sobre ela. São os corolários acima lidos de outra maneira: até os mais aparentemente banais gestos arquitetônicos nascem prenhes de sociabilidade porque são escolhas que implicam intrinsecamente consequências a 
afetarem nossos encontros ou esquivanças. Considerar a arquitetura como variável dependente ou independente é portanto um simples truque analítico, a opção por nos situarmos em certo ponto do círculo virtuoso. A SE foi acusada de "teoria determinista", ecos talvez dos equívocos dos pioneiros do Movimento Moderno (lembre Corbusier, 2006: "Arquitetura ou revolução. A revolução pode ser evitada"). Não bastasse a obviedade de não podermos projetar impunemente qualquer absurdo arquitetônico, um imenso acervo de pesquisa realizada nos quatro cantos do mundo utilizando os conceitos, método e técnicas da SE tem revelado como a arquitetura afeta a nossa vida, sem eliminar nosso arbítrio, ao criar um duplo campo: de possibilidades, que podem ou não ser exploradas segundo nossa vontade; de restrições, que podem ou não ser superadas segundo nossa capacidade (e, de novo, nossa vontade).

\section{A Arquitetura como disciplina}

Tida como arte, técnica, profissão, a Arquitetura merece o status de campo específico de saber - uma disciplina - a inquirir a realidade como nenhuma outra o faz. A especificidade foi exposta num dos textos seminais dos anos 1970, destarte escrito em parceria por Bill Hillier e Adrian Leaman: Architecture as a discipline (Hillier \& Leaman, 1976). É um truísmo dizer-se que o mundo é complexo, cuja compreensão exige uma multiplicidade de olhares. Entretanto, a completude só existe na realidade dos fatos: assim que lançamos sobre eles nosso olhar reflexivo, inevitavelmente priorizamos uns aspectos sobre outros, trazemos para a boca de cena certos atributos, deixamos no fundo do palco os demais. A ênfase na completude da empiria, da obviamente necessária interdisciplinaridade para compreendê-la, e da tradicional visão da arquitetura como campo no qual se aplicam saberes produzidos alhures, não como campo, ele próprio, construtor de saberes, tem reprimido a produção de conhecimento explícito $e$ específico em nossa área, fazendo a prática profissional apenas reproduzir o saber existente, subjacente e ignorante de si mesmo - não obstante intuições excepcionais que despontam aqui e ali. Ao revelar saberes aplicados mas ocultos, e, principalmente, descobrir novos saberes, a SE contribui para alçar a prática da arquitetura a novo patamar de qualidade, como são os exemplos de aplicação da teoria em projetos concretos, edilícios e urbanos, novamente, nos cinco continentes.

\section{Ciência é descrição}

Lembra-me u'a máxima dita com entusiasmo em seus seminários: ciência é descrição. Aparentemente isso contradiz a necessária explicação dos fenômenos, o desvelar de suas determinações, principalmente quando se trata do campo social. Ledo engano: a descrição profunda dos fatos exige a caracterização dos elementos que lhes constituem e das relações entre eles, que, para o que interessa à SE, focam a configuração dos lugares $x$ sistemas de encontros e esquivanças. Por exemplo, há analogia entre o isolamento físico de um lugar (distâncias, muralhas, terraplenos) e sua ocupação exclusiva por certos sujeitos (uma classe simbólica - política ou cerimonial), a conformarem o que chamei espaço de exceção (tema de minha tese) (Holanda, 2018); e sabemos que tais casos envolvem, milenarmente, profundas assimetrias sociais. Carece, naturalmente, perguntar: isso é bom ou ruim? Mas a resposta exige uma mudança de chave: agora estamos no campo da ética, no campo das escolhas e dos valores, a partir dos quais agimos para definir o mundo não como é (tarefa da ciência), mas como deve ser (tarefa da ética).

Com muita clareza, o historiador israelense Yuval Harari em seu livro Sapiens converge com Bill, quando observa que as questões "o que é bom?", ou "o que é certo?"

[...] não são questões científicas. A ciência pode explicar o que existe no mundo, como as coisas funcionam, e como poderiam ser no futuro. Por definição, não tem pretensão de saber o que deveriam ser no futuro. Somente religiões e ideologias procuram responder essas questões (Harari, 2017, p. 273, meus grifos).

Bill, portanto, como Harari, aproxima-se do "positivista lógico" (rótulos, ah! os rótulos...) Karl Popper para quem não há boas e más teorias, há as verdadeiras e as falsas aquelas que foram (até agora) comprovadas e aquelas que (já) foram refutadas pela evidência, respectivamente (Popper, 1976). Portanto, inserir a instância normativa no discurso científico não é apenas confusão, é 
erro crasso. A SE não é, pois, uma teoria normativa - uma contradição em termos, de qualquer forma - mas uma teoria que nos faculta tomar melhores decisões porque revela coisas do mundo que outras não conseguiram até então revelar.

\section{Quantidade e qualidade}

Certa colega, em certo momento, teve negado apoio para um projeto de pesquisa pelo $\mathrm{CNPq}$, e o parecer de um consultor entrou para o anedotário acadêmico: a aplicação da SE na pesquisa resumia-se à "matematização do óbvio" (não nomeio a colega por discrição, tampouco o consultor, pela óbvia anonimidade). Sim, Bill gosta de citar Galileu: "o mundo é matemático"; desconfia das armadilhas do discurso verbal e sua imprecisão para captar a complexidade e a sutileza das configurações edilícias e urbanas, daí porque desenvolve técnicas para descrever as non-discursive regularities (regularidades não-discursivas) do espaço arquitetônico; a questão está particularmente presente no seu segundo livro, Space is the machine (Hillier, 1996). Todavia, procurar reduzir a SE à sua "numerologia" é ignorar, p. ex., que quase metade de $S L S$ não lida com números, o mesmo ocorrendo com Space is the machine; na minha tese (repito, orientada por Bill), dos sete capítulos apenas o último trata a empiria quantitativamente; no meu livro bilingue sobre Oscar Niemeyer ( $D e$ vidro e concreto / Of glass and concrete) não uso um número sequer, tampouco "mapas axiais", a "técnica de convexidade", a "decomposição do espaço por isovistas", todos procedimentos afeitos à $\mathrm{SE}, \mathrm{e}, \mathrm{no}$ entanto, não poderia tê-lo escrito desconhecendo os conceitos basilares da teoria, particularmente os referentes às relações físicas (barreiras/permeabilidades) e visuais (opacidades/transparências) entre espaços internos e externos (Holanda, 2011); assim pude observar a sutileza com que Niemeyer aplica artifícios de monumentalidade milenares a seus edifícios, nas transições entre dentro e fora - rampas, passarelas sobre espelhos d'água, túneis, elevação do piano nobile, ilusões óticas mediante reflexos... ${ }^{2}$

\section{Três eixos}

Em fascinante livro recente - From Bacteria to Bach and Back (Dennet, 2017) - Daniel Dennet trata da evolução das mentes e das práticas que elas facultam. Sugere que a evolução se deu ao longo de três eixos: 1) debaixo-para-cima $\rightarrow$ de-cima-para-baixo (bottom-up $\rightarrow$ top-down): por um lado, ações pontuais que resultam num todo estruturado, inconcebido de antemão (como as formigas ao construírem o formigueiro); por outro, um todo é concebido a priori, para cuja realização ajustam-se incontáveis sujeitos sociais; 2) incompreensão $\rightarrow$ compreensão: por um lado, a realização inconsciente, irracional, instintiva; por outro, a realização consciente, reflexiva; 3 ) tentativa e erro $\rightarrow$ pesquisa sistemática: por um lado, aprender fazendo erraticamente, deduzir da experiência prática; por outro, fazer a partir de observar, ordenar, registrar, testar, provar, abstrair, generalizar.

Bela síntese do que Bill propunha... quarenta anos atrás, com um plus. De trás pra frente, mediante: 3) sua ênfase no conhecimento objetivo, muito referido a Popper - o rigor da investigação e a importância de vasto universo empírico, do que $S L S$ é exemplar; 2) sua discriminação epistemológica dos dois tipos de conhecimento: o científico e o social, este último inconsciente de si mesmo, porém subjacente a toda e qualquer realização humana - arquitetônica inclusa - resgatável $a$ posteriori pela razão; 1) as estruturas emergentes, das quais a cidade é paradigma este é o plus: não se trata de uma "evolução", como quer Dennett, mas de vertentes que vão e vêm, ao sabor das circunstâncias sociais. A história de Brasília ilustra a vertente topdown no Plano Piloto, mas também a bottomup na antiga Vila Paranoá, assentamento autoproduzido pelos trabalhadores, riscado do mapa em 1989 pelo governo local.

Por ocasião de sua primeira visita a Brasília (1986), mostramos o trabalho sobre a Vila em desenvolvimento pelos alunos, sob a liderança de Cláudio Acioly e sob minha orientação. Levei-o ao lugar, entrávamos e saíamos das ruas e vielas, ele absolutamente fascinado, parecia uma criança diante de um brinquedo novo... Foi difícil arrancá-lo de lá - guardo essa visita na memória com muito carinho. A Vila decerto contribuiu (minha dedução) para a formulação posterior do conceito de "roda deformada" como a configuração arquetípica dos assentamentos 
humanos "urbanos" - ou bottom-up: subjacente à irregularidade geométrica perceptível pelos sentidos, há uma poderosa ordem abstrata compreensível pela mente, constituída por vias mais longas, mais curtas, mais largas, mais estreitas, ausência de becos sem saída, proliferação de anéis de permeabilidade que se interceptam, inteligibilidade do local (apesar da irregularidade) facultada por estarmos sempre a poucos passos de um elemento "globalizador" (os eixos mais importantes que conferem organicidade ao todo), abundância de portas e janelas abrindo até para os diminutos e recônditos espaços formados pelos quarteirões mais segregados... Ele aqui reencontrava a configuração dos vilarejos do sul da França (e de tantos outros sítios mundo fora) que o encantaram e à Julienne, registrados em $S L S$ e em outros escritos. Tanto quanto recordo, não ouvi palestra posterior sua que não referisse a Vila Paranoá.

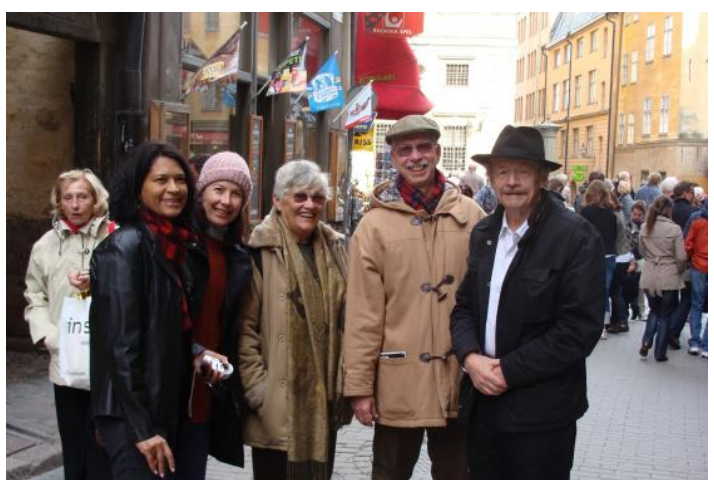

Figura 1. Depois de chegar a Estocolmo, para o $7^{\circ}$ Simpósio Internacional de Sintaxe Espacial

(2009), fomos dar um passeio por Gamla Stan, a parte medieval de Estocolmo. Escolhemos a 'linha vermelha' do mapa axial da ilha. Para aqueles não familiarizados com a gíria sintática, é, digamos, a rua mais "central", rigorosamente apontada pelas técnicas da teoria. Ela reza que a chance de encontrar alguém por acaso ali é maior

Bingo!!! Demos de cara com Bill Hillier, que vinha na direção oposta. A foto, tirada por Silvio

Cavalcante, registra o lindo momento. Da esquerda para a direita: Franciney França, Sandra Mello, Rosa de Lima Cunha, Fred Holanda e Bill Hillier.

Também me lembra o orgulho que senti quando ele visitou nossa casa em Brasília (2003) com sua esposa, Sheila Hillier: ao percorrermos o espaço deliciou-se com os "anéis de permeabilidade" que facultam rotas diversas entre dois pontos quaisquer... Aos queridos visitantes juntaram-se os membros do nosso grupo de pesquisa para uma "janta" tipicamente brasileira que lhes encantou: canjica, pamonha, pé-de-moleque, bolo de macaxeira, mungunzá, tapioca, cocada, bolo de goma, queijo de coalho...

\section{Projeto como conjectura-teste}

É comumente tido que o projeto de arquitetura é um processo de análise-síntese a desembocar numa proposta. Não para Bill, quando aborda a questão em Space is the Machine, ao resgatar a questão da intuição e da criatividade, que vale cita por extenso dada a importância do trecho:

O objeto do pensamento do arquiteto é uma configuração, e uma configuração é um todo, não uma acumulação de partes. Isso, claro, é o que queremos dizer por uma conjectura de projeto. É uma aposta configuracional. Não pode ser de outra maneira, pois não se pode chegar a uma configuração mediante um processo aditivo. (...) Um processo de conjectura configuracional só pode proceder não discursivamente. Não pode seguir um procedimento racional, nem proceder aditivamente de-baixopara-cima. $\mathrm{O}$ projeto é por natureza holístico, intuitivo, e chegamos a esta conclusão a partir de uma análise racional do próprio processo de projeto. $^{3}$

Eis o típico processo top-down como referido por Dennett: ao contrário do fenômeno arquetípico da cidade - bottom-up - o projeto arquitetônico é tipicamente top-down, como na Sagrada Família de Gaudí, que Dennett aprecia citar. Isto não quer dizer incompatibilidade com os eixos 2 e 3 acimaos da compreensão racional e da pesquisa sistemática: elas preestruturam o lançamento da conjectura tanto quanto podem simular, antes da realização, os efeitos que podem ter (aplicativos cada vez mais sofisticados são aqui instrumentos preciosos). Essa profícua relação entre intuição e racionalidade faz Bill elegantemente observar: "Arquitetura (...) é o emprego da intuição em um campo estruturado pela razão, e neste sentido podemos chamar a arquitetura de a arte racional". 4

\section{Marxismo, estruturalismo, positivismo? Ou...}

Na construção de seu pensamento, Bill dialoga com autores tão díspares quanto Marx, Durkheim, De Saussure, Lévi-Strauss, 
Popper, Foucault, Bourdieu, Giddens, Hobsbawn... Isso sói causar espécie em mentes bem-comportadas - a perplexidade fá-las tachá-lo, já de estruturalista, já de positivista, já de funcionalista... Contudo, ouvi dele próprio ser a luta de classes "motor da história" (lembra alguém?), mas classe aqui, como quaisquer outros conceitos que passam por seu crivo, repensada heterodoxamente como "grupos em oposição estrutural", oposição que não inclui apenas a dimensão econômica mas abarca a simbólica, a política, e a... espacial: há sociedades "primitivas" sem a propriedade privada dos meios de produção que, no entanto, para ele, são clivadas em classes antagônicas, a distinção marcada por gênero e qualificada por diferentes capitais simbólicos, políticos e arquitetônicos - tome os bororos no atual

\section{Notas}

${ }^{1}$ Bill apreciava a "cidade parque" de Lucio Costa, "uncompromisingly modern" ["moderna sem concessões"], como afirmou certa vez. Inspirado por nossas andanças no Plano Piloto, dediquei-lhe meu filme Deserto, lançado em 2018. Apreciou-o e escreveu-me afetuosa mensagem de agradecimento. (Disponível em: https://www.youtube.com/watch?v=RAqtd82YVI\&amp;t=97s Acesso em: 14.12.2019.) A notícia de sua morte me colheu em nossa casa de praia, no litoral cearense. Dediquei-lhe in memoriam um filme que estava a preparar, A arquitetura da luz. Sabia de seu gosto por Philip Glass, e utilizei-o na trilha sonora. Imagino-o ironicamente a sorrir do tom "fenomenológico" da nova película... (Disponível em: https://www.youtube.com/watch?v=njx2Pvkoao\&amp;t=3s Acesso em: 12 dec. 2019).

${ }^{2}$ Para uma discussão de técnicas discursivas e não-discursivas (ou "qualidade" e "quantidade") relacionadas à SE, ver NETTO, Vinicius $M$. "What is space syntax not?": Reflections on space syntax as sociospatial theory. Urban Design International, London, vol. 21 (1), p. 25-40, 2016.

${ }^{3}$ No original: "The object of the architect's thought is a configuration, and a configuration is

\section{Referências}

Corbusier, L. (2006). Por uma arquitetura. São Paulo, Perspectiva.

Dennett, D. C. (2017). From bacteria to Bach and back: The evolution of minds. London, WW Norton \& Company.

Giddens, A. (1973). The class structure of the advanced societies. London, Hutchinson of London. território brasileiro, ou os zulus na África pré-colonial. $^{5}$

Como grande sujeito do seu tempo, há muitas frentes nas quais Bill Hillier reinventa a reflexão e a ação; refere os gigantes sobre cujos ombros trabalha, só não diz que passa a constituir a família, inovando teórica, metodológica, técnica e praticamente, legando por sua vez generosos ombros nos quais pousamos.

Em meu nome e em nome dos seus netos (e bisnetos!) acadêmicos do nosso grupo de pesquisa na Universidade de Brasília, muito obrigado, Mestre!

a whole entity, not an accumulation of parts. This of course is what we mean by a design conjecture. It is a configurational guess. It cannot be otherwise, since configuration cannot be arrived at by an additive process. (...) A process of configurational conjecture cannot proceed other than non-discursively. It cannot therefore either follow a reasoned procedure, nor can it proceed additively from the bottom up. Design is by nature a holistic, intuitive process, and this conclusion follows from a reasoned analysis of the process of design" (minha tradução). (Hillier, 1996, p. 421)

${ }^{4}$ No original: "Architecture (...) is the deployment of intuition within a field structured by reason, and in this sense we may call architecture the reasoning art" (minha tradução; gratidão a Edja Trigueiro, Diógenes Falcão Pereira e Luiz Amorim por sugestões). (Hillier, 1996, p. 411).

${ }^{5}$ Exploro a noção de capital arquitetônico em HOLANDA, Frederico de. Construtores de mim. Brasília: FRBH, 2019; sobre os zulus, ver minha tese, citada, O espaço de exceção.

Giddens, A. (1984). The constitution of society: Outline of the theory of structuration. Cambridge, Polity Press.

Harari, Y. N. (2017). Sapiens: uma breve história da humanidade. Porto Alegre, L\&PM.

Hillier, B., \& Leaman, A. (1976). Architecture as a discipline. Journal of Architectural Research, 5(1), 28-32.

Hillier, B., \& Hanson, J. (1989). The social logic of space. Cambridge, Cambridge University Press. 
Hillier, B. (1996). Space is the machine. Cambridge, Cambridge University Press.

Holanda, F. D. (2011). Oscar Niemeyer: de vidro e concreto. Of Glass and Concret. Brasília, FRBH.

Holanda, F. D. (2018) O espaço de exceção. (2), Brasília, FRBH. Disponível em: https://www.academia.edu/36395002/O_ESPA\%
C3\%87O_DE_EXCE\%C3\%87\%C3\%83O_Livro _completo_. [Consultado em: 16 out. 2019].

Popper, K. (1976). Conjectures and refutations the growth of scientific knowledge. London, Routledge and Kegan Paul. 